Article

\title{
Investigation of the effect of freeze-thaw cycles on the mechanical properties of hardened self-compacting concrete
}

\author{
Tuncay Kap* \\ Duzce Vocational Higher School, Duzce University 81100, Turkey; tuncaykap@duzce.edu.tr \\ * Correspondence: tuncaykap@ hotmail.com; Tel: +90-506-7007481
}

\begin{abstract}
This study investigated the effects of freeze-thaw cycles on the mechanical properties of hardened self-compacting concrete for varying column heights. A column $(100 \times 20 \times 300 \mathrm{~cm})$ was fabricated by C30 self-compacting concrete in the laboratory and 10 cube samples $(10 \times 10 \times 10 \mathrm{~cm})$ were taken from fresh concrete as the references. After a period of 28 days, 160 core specimens (Ø67 $\mathrm{mm}$ in diameter) were taken from different column heights. Unit weight, water absorption, compressive strength, and freeze-thaw tests were performed on these 170 (10 reference cubic and 160 core) samples. The mechanical properties of the core specimens before freeze-thaw and after 8-56 freeze-thaw cycles were reported for varying column heights. The average compressive strength value of the reference cubic samples was determined as $40.28 \mathrm{MPa}$, while the compressive strengths of the core specimens before freeze-thaw were ranged from $40.25 \mathrm{MPa}$ to $49.62 \mathrm{MPa}$, impying an increase in compressive strength values up to $23.18 \%$ compared to the reference cubic samples. Compressive strengths of the specimens subjected to 8 and 56 freeze-thaw cycles varied between 38.71-48.07 MPa and 31.72-39.11 MPa, respectively. Statistical analysis revealed that the compressive strength of the concrete exposed to 56 freeze-thaw cycles was significantly different from that of the other specimens.
\end{abstract}

Keywords: Self-compacting concrete; core specimens; freeze-thaw; compressive strength.

\section{Introduction}

Self-compacting concrete (SCC), when placed in a form, can pass through obstructions by its own weight without the need of vibrations [1]. The increasing cost due to the use of chemical admixtures and high volumes of Portland cement is one of the disadvantages of SCC [2]. Use of finely divided mineral admixtures such as natural pozzolans fly ash, silica fume, etc, in SCC is a good way of reducing the cost, especially if these mineral admixtures are industrial by-products or wastes. Contribution of fly ash to the self-compacting properties of concrete has been demonstrated in a number of studies $[3,4,5]$. One of the important factors affecting the durability of concrete structures is the freeze/thaw cycle [6,7]. Freeze/thaw damage is generally observed at water-saturated conditions in concrete structures where temperature differences are constantly changing. Freeze/thaw cycles are experienced in many buildings around the world and consequently, structural elements are seriously damaged [8].

Freeze/thaw damage in concrete occurs only in voids of certain dimensions and with frost. No frost-induced cracking occurs in voids of less than $0.1 \mathrm{~mm}$. Various salts such as calcium hydroxide and alkali chlorides in dissolved form are present in the water in concrete voids [9]. Many researchers have investigated freeze/thaw-cycle damage in concrete. The use of artificial pozzolans produced from industrial waste was found to reduce freeze/thaw damage in SCC [10, 11]. Zhang et al. [12] replaced the cement in SCC with different amounts of fly ash and silica fume and applied a 90-cycle freeze/thaw test on 7-mm-cube samples. With the use of up to $40 \%$ fly ash, the freeze/thaw resistance was found to increase, but at higher rates, it caused damage at the same rate as in the 
control sample. Another study investigated the freeze/thaw resistance, mechanical performance, and rheology of SCC produced by using recycled coarse aggregate at ratios of $20 \%, 40 \%$, and $60 \%$ [13]. The experimental results revealed that the recycled coarse aggregate increased the viscosity of the concrete, but did not significantly affect its compressive strength. In addition, results from the freeze/thaw test showed that the freeze/thaw resistance decreased linearly with the resulting changes in weight as the percentage of the recycled aggregate increased [13]. Many researchers have investigated the impact of the freeze-thaw cycle on concrete. The use of artificial pozzolans as industrial waste in SCC has been observed to mitigate the freeze-thaw damage $[14,15]$. The freeze-thaw damage pattern of pervious concrete is different from that of ordinary concrete [16]. This study investigated the effects of freeze-thaw cycles on the compressive strength of a SCC-column. Within this context, 10 reference cubic specimens were prepared according to Turkish Standard TS EN 12350-1 and held in a curing tank for 28 days [17]. A column was fabricated by C30 self-compacting concrete in the laboratory and a total of 160 core specimens were obtained from different column heights. The mechanical properties of both reference cubic samples and core samples obtained from different column heights were determined before freeze-thaw and after 8-56 freeze-thaw cycles. The changes in the mechanical properties of SCC were reported.

\section{Material and Methods}

\subsection{Materials}

The CEM I 42.5 R type Portland cement, which complies with TS EN 197-1, supplied by the Oyak Bolu Cement factory was used in the experimental study [18]. Crushed stone (Dmax $16 \mathrm{~mm}$ ) obtained from local Duzce quarries was used as the aggregate. Grade F silica fly ash, classed as low-lime according to ASTM C618 standard, obtained from the Catalagzi thermal power plant was used as the pozzolan [19]. A polycarboxylate ether-based hyperplasticizer chemical additive, which reduced the water requirement to a great extent, was used in the SCC mixture at $1.06 \%$ of the cement weight [20]. The SCC was determined as concrete grade C30/37 and the water/cement (W/C) ratio was designed as 0.33 . Fresh concrete tests designed in the laboratory environment were conducted on the SCC and compliance criteria were met in accordance with the standards recommended by EFNARC [14].

The CEM I 42.5 R Portland cement was supplied by the Bolu Cement factory and used in the production of the concrete, in compliance with TS EN 197-1 standard; as a plasticizer additive, a high-performance polycarboxylate-based hyper-plasticizer was used.

\subsection{Mixing, Specimens Casting, and Curing Procedures}

The mixing ratios of SCC are given in Table 1.

Table 1. Self-compacting concrete mix design

\begin{tabular}{ccc}
\hline $\begin{array}{c}\text { SCC } \\
\text { (aggregate) }\end{array}$ & $\begin{array}{c}\text { C30/37 } \\
\text { (quantitiy kg) }\end{array}$ & $\begin{array}{c}\text { Consistency } \\
\text { (moisture content \%) }\end{array}$ \\
\hline 0-5 K & 1066 & 4.5 \\
5-15(Dmax:15) & 661 & 1.0 \\
CEM2 42.5R & 350 & \\
Hyperfluid & 5 & \\
Fly ash & 150 & \\
Water & 168 & \\
\hline Total & 2400 & \\
\hline
\end{tabular}

Self-compacting concrete, designed to have a water-cement ratio of 0.33 , was produced in the laboratory and placed in the molds [21]. The mold of the column was made out of plywood element with a section of 20x100 cm and a height of $300 \mathrm{~cm}$. Mold release oil was used on the mold surfaces before concrete casting. SCC was placed into the prepared molds with its own weight and no 
vibration was applied. After 24 hours following the concrete pouring, the column element was irrigated and cured. The produced concrete was kept in the laboratory at $20 \pm 3^{\circ} \mathrm{C}$ temperature and in an environment with $60 \%$ humidity.

\subsection{Testing Procedures}

Tests were carried out in compliance with specifications and guidelines for SCC decomposition flow, $\mathrm{T} 50 \mathrm{~cm}$ flow time, V-funnel flow time, 5-min delayed V-funnel flow time, L-box transition rate, and L-box flow time $[13,14]$. To reduce the loss of self-compacting ability over time, the properties of the mixtures in the fresh state were determined within $20 \mathrm{~min}$ of mixing [22]. Determination of the fresh concrete unit weight was carried out according to EN 12350-6 [23]. The EN 12390-3 [24] and ASTM: C597 standards were applied to determine the values for compressive strength, tensile stress, and ultrasonic pulse velocity in the $10 \mathrm{~cm}$ reference cube samples, respectively. Unit weight and water absorption values of the hardened SCC mixtures were established for the reference cubic samples in accordance with EN 12390-7 and TS 3624 standards, respectively [13,24].

The molds were removed seven days after the concrete was poured. Then, for 28 days, a wet cure was performed three times per day (morning, afternoon, and evening) at the construction site. The column was horizontally aligned in order to take the core samples easily. In order to determine the physical and mechanical properties of the SCC, core samples of $67 \mathrm{~mm}$ diameter were taken at 15 $\mathrm{cm}$ intervals from the bottom of the column [25]. In addition to the 10 previously prepared $10 \mathrm{~cm}$ cube reference specimens, a total of 160 samples (diameter $67 \mathrm{~mm}$, height $134 \mathrm{~mm}$ ) were taken (Fig. $1)$.

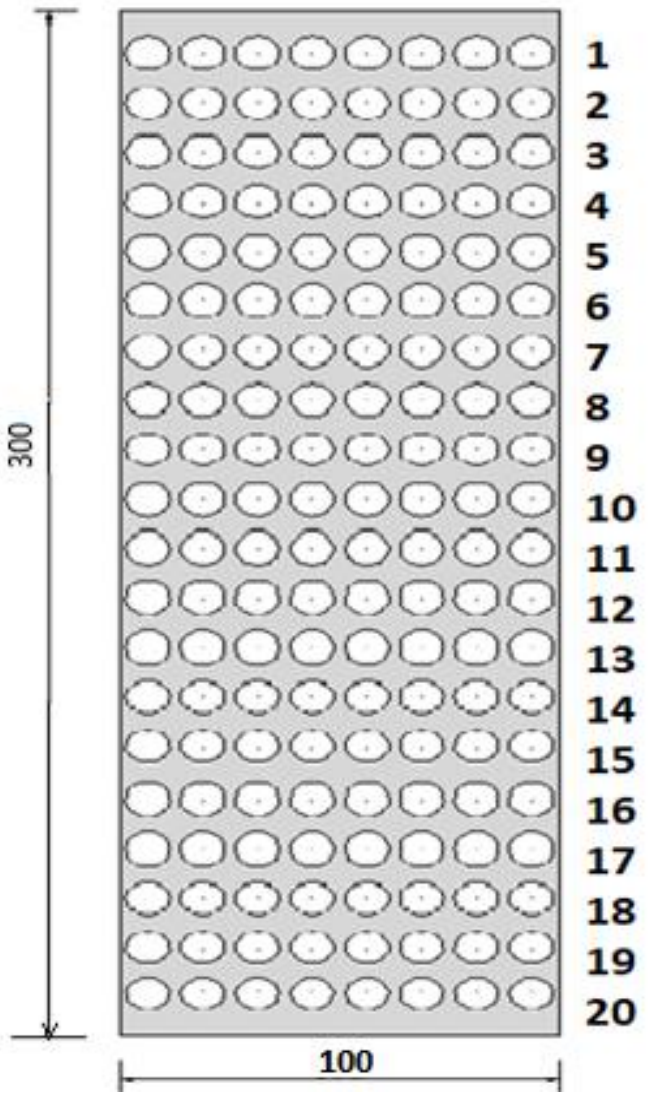

Figure 1. A Schematic showing of the core specimens on the column 


\subsection{Determination of Physical Properties}

After being held for 28 days in the laboratory, all the specimens were measured for their air-dry weights at a sensitivity of $0.1 \mathrm{~g}$. The core unit weight and water absorption tests were carried out on reference cubic specimens and core samples taken from different heights of the column. The samples were immersed in water for 24 hours, then saturated dry surface was calculated with the help of formulas to obtain unit volume weight and water absorption data and are shown in Table 2.

Table 2. Properties and column height of SCC core specimens

\begin{tabular}{|c|c|c|c|}
\hline $\begin{array}{l}\text { Core } \\
\text { specimens } \\
\text { on the } \\
\text { column }\end{array}$ & $\begin{array}{l}\text { Natural unit } \\
\text { volume } \\
\text { weight } \\
\left(\mathrm{kg} / \mathrm{m}^{3}\right) \\
(\mathrm{X} 1)\end{array}$ & $\begin{array}{l}\text { Amount of } \\
\text { water } \\
\text { absorption } \\
(\%) \\
(\mathrm{X} 2)\end{array}$ & $\begin{array}{l}\text { Column } \\
\text { height }(\mathrm{cm})\end{array}$ \\
\hline 1 & 2372 & 2.384 & 285 \\
\hline 2 & 2374 & 2.376 & 270 \\
\hline 3 & 2375 & 2.366 & 253 \\
\hline 4 & 2378 & 2.358 & 238 \\
\hline 5 & 2381 & 2.351 & 224 \\
\hline 6 & 2384 & 2.345 & 210 \\
\hline 7 & 2388 & 2.331 & 196 \\
\hline 8 & 2390 & 2.224 & 182 \\
\hline 9 & 2393 & 2.210 & 168 \\
\hline 10 & 2397 & 2.196 & 154 \\
\hline 11 & 2399 & 2.184 & 140 \\
\hline 12 & 2404 & 2.146 & 126 \\
\hline 13 & 2409 & 1.984 & 112 \\
\hline 14 & 2413 & 1.923 & 98 \\
\hline 15 & 2418 & 1.897 & 84 \\
\hline 16 & 2419 & 1.846 & 70 \\
\hline 17 & 2423 & 1.791 & 56 \\
\hline 18 & 2426 & 1.725 & 42 \\
\hline 19 & 2438 & 1.713 & 28 \\
\hline 20 & 2431 & 1.680 & 14 \\
\hline $\begin{array}{l}\text { Reference } \\
(10 \mathrm{~cm} \text { cube })\end{array}$ & 2400 & 2.35 & - \\
\hline
\end{tabular}

$X 1$ : Natural unit volume weight $\left(\mathrm{kg} / \mathrm{m}^{3}\right)$

X2: Amount of water absorption (\%)

X3: Column height $(\mathrm{cm})$

\section{Freeze-Thaw Test}

A rapid F-T chamber was used based on the ASTM C66 standard specifications to create frequent F-T cycles which were consisted of reducing the specimen temperature from +4 to $-18^{\circ} \mathrm{C}$ and subsequently increasing it from -18 to $+4{ }^{\circ} \mathrm{C}$ over a period of $5 \mathrm{~h}[26,27]$. Temperature variation curve during F-T cycles is shown in Figure 2. 


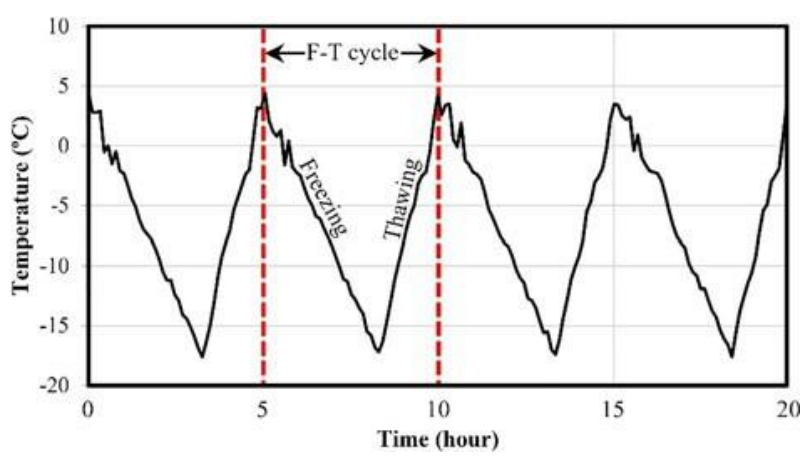

Figure 2. Air temperature variations in the freeze-thaw cycles as a function of time

The freeze-thaw test was applied on the samples in 8 and 56 cycles. Experiments were performed by completing each cycle at temperatures ranging from $-20^{\circ} \mathrm{C}$ to $+20^{\circ} \mathrm{C}$ and a total of 1 cycle in 5 hours. The freeze-thaw test of these concrete specimens was conducted after 28 days. After the specimens were submerged in a water bath and dried with a towel, the mass of each specimen was measured Fig 3 and Fig 4 .

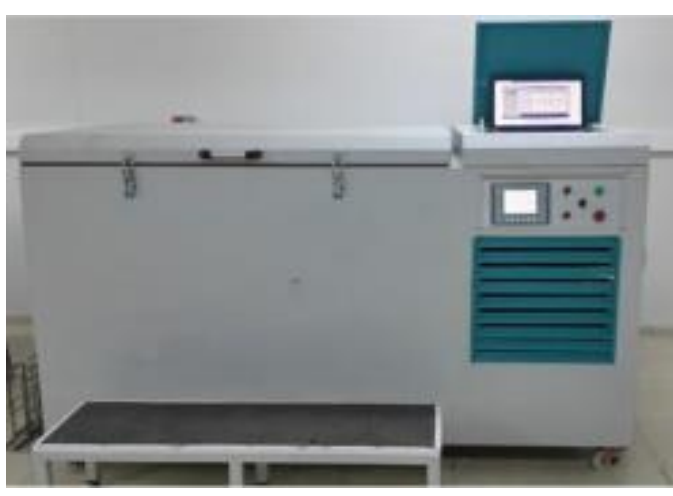

Figure 3. Freeze-thaw test device

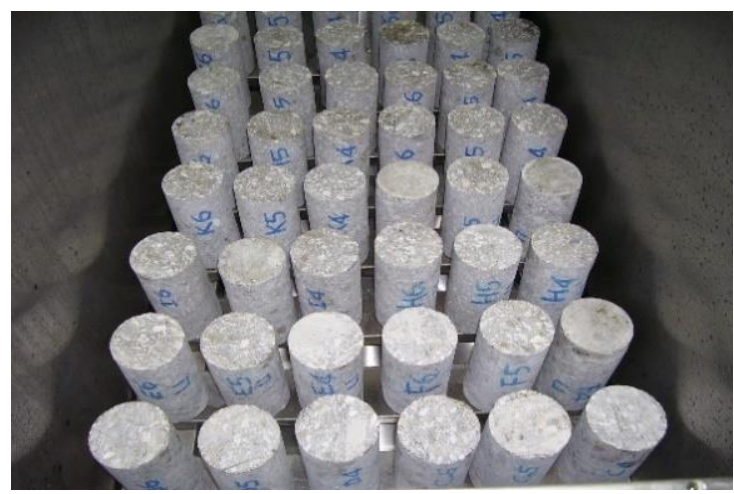

Figure 4. Freeze-thaw test of core specimens

The specimens were placed vertically into the freeze-thaw cabinet. Specimens placed in the freeze-thaw cabinet were rotated $180^{\circ}$ once a week so that the upper surfaces of the specimens were placed on the base of the cabinet. The specimens were placed at distances of at least $60 \mathrm{~mm}$ from each other and from the cabin wall. The compressive strengths of the reference cube and concrete test specimens were determined after 8 and 56 cycles [28] (Table 3). 
Table 3. Compressive strength results according to freeze-thaw cycle

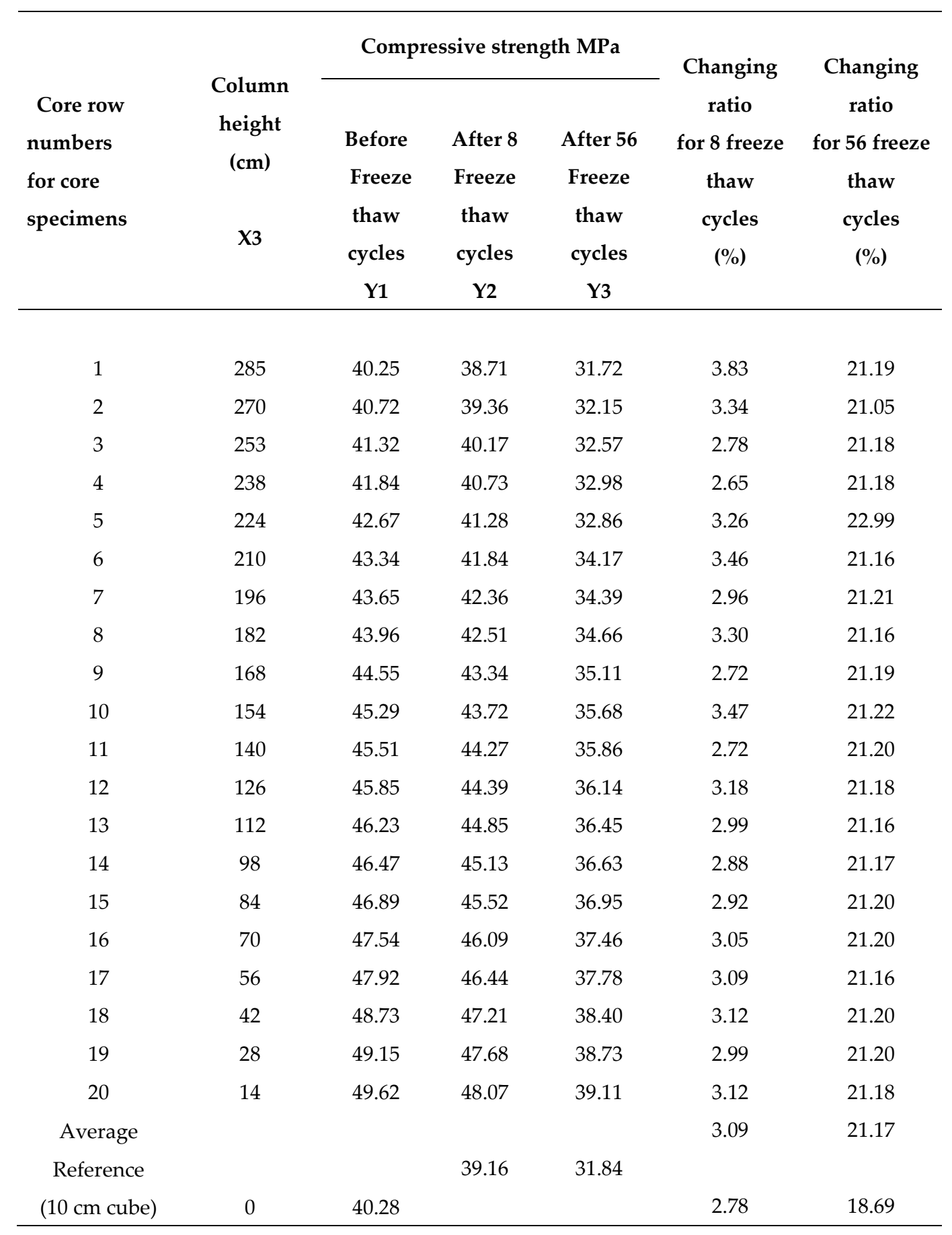




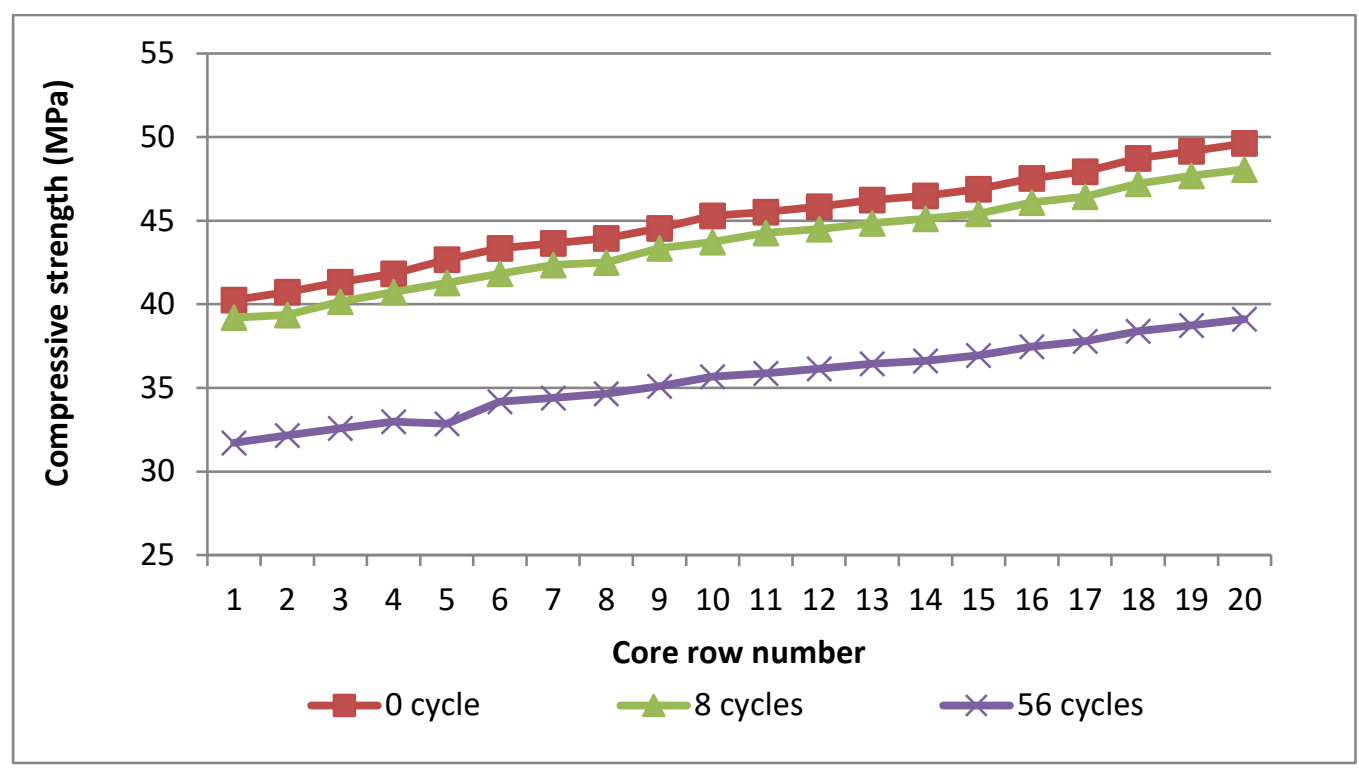

Figure 5. Compressive strengths of 0-, 8-, and 56-cycle freeze-thaw specimens

Tests were performed on core cylinder samples $67 \times 134 \mathrm{~mm}$ in size. The compressive strengths of the core specimens being subjected to 8 and 56 freeze-thaw cycles were compared to the compressive strength of core specimens that were not subjected to any freeze-thaw cycle. Comparison of the averages of $\mathrm{Y} 2$ and $\mathrm{Y} 3$ data with that of $\mathrm{Y} 1$ revealed that $\mathrm{Y} 2$ and $\mathrm{Y} 3$ data had a loss of $3.09 \%$ and $21.17 \%$, respectively. The compressive strengths of the core samples taken approximately $15 \mathrm{~cm}$ apart from the bottom and the uppermost points of the column were evaluated among each other. The ratio of the compressive strength of the sample at the uppermost point of the column to the compressive strength of the sample (20) at the bottom of the column for Y1 was calculated as $81 \%$. Similarly, the ratio of the compressive strength of the sample at the middle height to the one at the bottom was determined as $89 \%$. On the other hand, these ratios were calculated as $80 \%$ and $91 \%$ for $\mathrm{Y} 2$ and $81 \%$ and $91 \%$ for $\mathrm{Y} 3$. Comparison of the freeze/thaw resistance data of the samples taken from the uppermost, middle, and bottom points revealed that the series had different values changing in accordance with the amount of the voids.

- The average compressive strength value of the reference cubic specimens was $40.28 \mathrm{MPa}$, while that of non-subjected specimens varied from $40.25 \mathrm{MPa}$ to $49.62 \mathrm{MPa}$.

- The compressive strength of the specimens subjected to 8 freeze-thaw cycles varied between $38.71 \mathrm{~N} / \mathrm{mm}^{2}$ and $48.07 \mathrm{MPa}$ depending on the column height.

- The compressive strength of the specimens after 56 freeze-thaw cycles varied between 31.72 $\mathrm{MPa}$ and 39.11 MPa [29].

- The core specimens exposed to 56 freeze-thaw cycles exhibited a significantly different compressive strength from that of the specimens subjected to 8 freeze-thaw cycles and the non-subjected ones [30].

\section{Data Analysis}

\subsection{Descriptive Statistics}

The descriptive statistics of specimens generally include the value range, arithmetic mean, standard error, standard deviation, and variance parameters. The descriptive statistics of the specimens are given in the table below (Table 4). 
Table 4. Descriptive statistics of the specimens

\begin{tabular}{|c|c|c|c|c|c|c|c|c|}
\hline \multirow{3}{*}{ Parameters } & \multirow{3}{*}{$\begin{array}{c}\text { N } \\
\text { Statistic }\end{array}$} & \multirow{3}{*}{$\begin{array}{c}\text { Range } \\
\text { Statistic }\end{array}$} & \multicolumn{4}{|c|}{ Descriptive Statistics } & \multirow{3}{*}{$\begin{array}{c}\text { Std. } \\
\text { Deviation } \\
\text { Statistic }\end{array}$} & \multirow{3}{*}{$\begin{array}{l}\text { Variance } \\
\text { Statistic }\end{array}$} \\
\hline & & & \multirow{2}{*}{$\begin{array}{l}\text { Minimum } \\
\text { Statistic }\end{array}$} & \multirow{2}{*}{$\begin{array}{c}\text { Maximum } \\
\text { Statistic }\end{array}$} & \multicolumn{2}{|c|}{ Mean } & & \\
\hline & & & & & Statistic & Std. Error & & \\
\hline $\mathrm{X} 1$ & 20 & 0.15 & 2.53 & 2.67 & 2.6126 & 0.00922 & 0.04125 & 0.002 \\
\hline $\mathrm{X} 2$ & 20 & 2.26 & 3.49 & 5.75 & 4.7680 & 0.15768 & 0.70516 & 0.497 \\
\hline X3 & 20 & 271.00 & 14.00 & 285.00 & 147.500 & 18.6990 & 83.6247 & 6993.10 \\
\hline Y1 & 20 & 9.37 & 40.25 & 49.62 & 45.0750 & 0.63112 & 2.82245 & 7.966 \\
\hline $\mathrm{Y} 2$ & 20 & 9.36 & 38.71 & 48.07 & 43.6835 & 0.61906 & 2.76850 & 7.665 \\
\hline $\mathrm{Y} 3$ & 20 & 7.39 & 31.72 & 39.11 & 35.4900 & 0.50534 & 2.25996 & 5.107 \\
\hline
\end{tabular}

\subsection{Correlation Analysis}

The relationship between the physical properties of the concrete specimens and the compressive strengths obtained at the end of the freeze-thaw cycles were tested and the correlation coefficients between them are shown in the following correlation table with a 95\% confidence interval [31] (Table 5).

Table 5. Correlation coefficients between the physical properties of concrete specimens and concrete compressive strengths

\begin{tabular}{|c|c|c|c|c|c|c|}
\hline Parameters & $\mathbf{X 1}$ & $\mathrm{X} 2$ & $\mathrm{X3}$ & Y1 & $\mathrm{Y} 2$ & Y3 \\
\hline \multirow{2}{*}{ Y1 } & \multirow{2}{*}{$0.995^{* *}$} & $0.986^{*}$ & -0.99 & \multirow{2}{*}{1} & 0.999 & $0.997^{*}$ \\
\hline & & $7^{*}$ & & & ${ }^{*}$ & \\
\hline $\mathrm{Y} 2$ & $0.995^{* *}$ & $\begin{array}{r}0.986^{*} \\
7^{*}\end{array}$ & -0.99 & 0.999 & 1 & $0.996^{*}$ \\
\hline Y3 & $0.987^{* *}$ & $0.987^{*}$ & $-0.995^{* *}{ }_{x x}$ & $0.997_{* *}$ & 0.996 & 1 \\
\hline
\end{tabular}

**. Correlation is significant at the 0.01 level (2-tailed).

\subsection{Multiple Comparison Test}

A significant difference between the averages of two or more distribution groups can be determined by variance analysis ( $F$ test or ANOVA). The F test was applied to determine whether a significant difference exists among the compressive strength averages of the groups and two hypothesis were developed as follows:

H0: No significant difference exists between the averages $(p \geq 0.05)$.

H1: A significant difference exists between the averages $(p<0.05)$.

In the experimental studies, specimens subjected to 0,8 , and 56 freeze-thaw cycles were used to determine the difference between the groups in terms of concrete compressive strength. Analysis results are given below (Table 6). 
Table 6. Results of variance analysis for concrete compressive strength

\begin{tabular}{|c|c|c|c|c|c|}
\hline \multicolumn{6}{|c|}{ ANOVA } \\
\hline & & & Mean & & \\
\hline & Sum of Squares & $\mathrm{df}$ & Square & $\mathrm{F}$ & Sig. \\
\hline Between Groups & 1072.946 & 2 & 536.473 & 77.606 & 0.000 \\
\hline Within Groups & 394.027 & 57 & 6.913 & & \\
\hline Total & 1466.973 & 59 & & & \\
\hline
\end{tabular}

As a result of the variance analysis, the signification value at a $95 \%$ confidence interval was found to be 0.000 . Because the $\mathrm{F}$ value calculated from the variance analysis was lower than the $\mathrm{F}$ table value $(p<0.05)$, a significant difference was found between the groups in terms of concrete compressive strengths, which shows that hypothesis H1 was valid. In order to compare the difference between each group separately, the Scheffe test was used as a multiple-comparison test (Table 7).

Table 7. Multiple comparison results

\begin{tabular}{|c|c|c|c|c|c|c|c|c|}
\hline \multirow{3}{*}{ (I) Groups } & & & & \multirow{3}{*}{$\begin{array}{l}\text { Mean } \\
\text { Difference } \\
\text { (I-J) }\end{array}$} & \multirow{3}{*}{$\begin{array}{l}\text { Std. } \\
\text { Error }\end{array}$} & & \multicolumn{2}{|c|}{ 95\% Confidence Interval } \\
\hline & & & & & & & Lower & Upper \\
\hline & & \multicolumn{2}{|l|}{ (J) Groups } & & & Sig. & $\underline{\text { Limit }}$ & Limit \\
\hline \multirow{6}{*}{ Dimension2 } & \multirow[t]{2}{*}{ Y1 } & \multirow{2}{*}{ dimension3 } & Y 2 & 1.39150 & 0.83 & 0.250 & -0.6983 & 3.4813 \\
\hline & & & Y 3 & $9.58500^{*}$ & 0.83 & 0.000 & 7.4952 & 11.6748 \\
\hline & \multirow[t]{2}{*}{ Y2 } & \multirow{2}{*}{ dimension3 } & Y 1 & -1.39150 & 0.83 & 0.250 & -3.4813 & 0.6983 \\
\hline & & & Y 3 & $8.19350^{*}$ & 0.83 & 0.000 & 6.1037 & 10.2833 \\
\hline & \multirow{2}{*}{ Y3 } & \multirow{2}{*}{ dimension3 } & Y 1 & $-9.58500^{*}$ & 0.83 & 0.000 & -11.6748 & -7.4952 \\
\hline & & & $\mathrm{Y} 2$ & $-8.19350^{*}$ & 0.83 & 0.000 & -10.2833 & -6.1037 \\
\hline
\end{tabular}

* Mean difference of 0.05 is significant.

As a result of multiple comparison tests, no significant difference was found between the compressive strength values of the non-subjected groups and those obtained as a result of 8 freeze-thaw cycles. However, the compressive strength values of the concrete specimens exposed to 56 freeze-thaw cycles were significantly different both from the values of those subjected to 8 freeze-thaw cycles and of the non-subjected ones. The distribution of the sub-groups formed as a result of the analysis is presented below (Table 8).

Table 8. Distribution of sub-groups as a result of analysis

\begin{tabular}{|c|c|c|c|c|}
\hline \multicolumn{5}{|c|}{ Scheffe ${ }^{a}$} \\
\hline \multicolumn{2}{|c|}{ Groups } & \multirow[b]{2}{*}{$\mathrm{N}$} & \multicolumn{2}{|c|}{ Subset for alpha $=0.05$} \\
\hline & & & 1 & 2 \\
\hline \multirow{4}{*}{ Dimension1 } & Y3 & 20 & 35.4900 & \\
\hline & Y2 & 20 & & 43.6835 \\
\hline & Y1 & 20 & & 45.0750 \\
\hline & Sig. & & 1.000 & 0.255 \\
\hline \multicolumn{5}{|c|}{$\begin{array}{l}\text { Means for groups in homogeneous subsets are displayed } \\
\text { a. Uses harmonic mean sample size }=20.000 \text {. }\end{array}$} \\
\hline
\end{tabular}




\section{Conclusion}

In this study, the effects of freeze-thaw cycles on the mechanical properties of hardened SCC were investigated experimentally for varying column heights and the obtained data were analyzed statistically. The results were obtained as follows:

- An average of $3.09 \%$ and $21.17 \%$ decrease was observed in the compressive strength of core specimens after 8 and 56 freeze-thaw cycles, respectively.

- The highest losses in the compressive strength values of core specimens after 8 and 56 cycles were observed as $3.83 \%$ and $22.99 \%$, respectively.

- When the compressive strength data of the non-subjected samples were compared, it was determined that the compressive strength of the non-subjected samples in the lower region was approximately $20 \%$ higher than the upper region and 10\% higher than the middle region.

- According to the compressive strength data obtained as a result of the freeze-thaw cycles of 8 and 56, it was found that the compressive strength changes similar to those seen in the non-subjected samples.

- In the core sample taken at the bottom of the column having a height of $300 \mathrm{~cm}$, the unit weight was found to be $3 \%$ higher than the unit weight of the sample taken at the top.

- When the water absorption data of the concrete were examined, the water absorption values of the lower point where the void ratio was lower and the highest point with the highest void ratio were recorded as $1.68 \%$ and $2.38 \%$, respectively.

According to these findings:

- The compressive strength significantly decreased in the regions of the concrete subjected to frequent and intensive freeze-thaw cycles.

- The decrease in concrete compressive strength should be taken into consideration in the calculation and design of reinforced concrete structures in areas exposed to freezing-thawing.

- The decrease in the concrete compressive strengths values should be determined and taken into consideration when planning reinforced concrete structures in these regions.

In case the freeze-thaw cycle is excessive, the decrease in concrete compressive strength should be investigated in more detail and the effects of long-term freeze-thaw on the compressive strength and other engineering properties of the concrete should be examined from various angles. According to the results of this research, the reduction coefficients of the non-subjected specimen values should be established and the reduced values should be taken into account in the calculations and design of reinforced concrete elements.

Acknowledgments: The authors would like to appreciate anonymous reviewers for their constructive suggestions and comments to improve the quality of the paper.

Conflicts of Interest: The authors declare no conflict of interest. 


\section{References}

1. Okamura, H., Ouchi, H., Self-compacting concrete, Journal of Advanced Concrete Technology, 2003; Volume 1, pp. 5-15.

2. Sahmaran. M, Christianto. H. A., Yaman. O.I., The effect of chemical admixtures and mineral additives on the properties of self-compacting mortars, Cement and Concrete Composites, 2006; Volume (28) pp. 432-440.

3. Erdogan, T.Y., Admixtures for Concrete, METU Press, 1997, Ankara, Turkey.

4. Bilodeau, A. And Malhotra, V.M., High-volume fly ash system: concrete solution for sustainable development, ACI Mater. J., 2000; Volume 97(1), pp. 41-48.

5. Onat, O. and Celik, E., An a integral based fuzzy approach to evaluate waste materials for concrete, Smart Structure. Syst, 2017; Volume 19(3), pp 323-333.

6. Aldaood, A., Bouasker, M; Al-Mukhtar, M; Effect of water during freeze-thaw cycles on the performance and durability of lime-treated gypseous soil, Cold Region Sci. Technol., 2016, Volume 123, pp. 155-163.

7. Hameed, M; Sekar, S; Saraswathy, V., Strenght and permeabilty characteristics study of self-compacting concrete using crusher rock dust and marble studge powder, Arabian Journal for Science Engineering, 2012, Volume, 37(3), pp. 561-574.

8. Zhang, D; Mao, M; Zhang, S; Yang, Q; Influence of stress damage and high temperature on the freeze-thaw resistance of concrete with fly ash as fine aggregate, Construction and Building Materials, 2016, Volume 119, pp. 241-250.

9. Yalcin, H; and Guru, H; Cement and Concrete, Palme publishing, Ankara, 2006, pp. 204-209.

10. Yazıc1, H; The effect of silica fume and high-volume Class $\mathrm{C}$ fly ash on mechanical properties, cloride penetration and freeze-thaw resistance of Self-compacting concrete, Construction and Building Materials, 2008, Volume 22(4), pp. 456-462.

11. Chung, C,W; Shon, C,H; C,S; Kim, C,S; Chloride ion difusivity of fly ash, silica fume concretes exposed to freeze-thaw cycles, Constr. Build. Materials, 2010, Volume 24(9) pp. 1739-1745.

12. Zhang, P., Li, Q., Sun, Z., Effect of polypropylene fibre on flexural properties of concrete composites containing fly ash and silica fume, Proceedings of the Institution of Mechnical Engineers Part L, Journal of Materials Design and Applications, 2012, Volume (226) 2, pp. 177-181.

13. Tuyan, M; Mardani, A; Ramyar, K; Freeze-thaw resistance, mechanical and transport properties of self-consolidating concrete incorporating coarse recycled concrete aggregate, Materials and Design,2014, Volume (53) pp. 983-991.

14. EFNARC, The European Guidelines for Self- Compacting Concrete, http://www.efnarc.org/pdf/SCCGuidelines pdf [accessed 30.07.13], 2005.

15. Nevilla, A.M., Properties of Concrete, 5 th ed., Pearson Education, England, pp. 602-603, 2011.

16. Hanbing, L; Goobao, L; Haibin, W and Han, Y; Strenght, permeabilty, and freeze-thaw durability of pervious concrete with different aggregate sizes, porosities, and water-binder ratios, MDPI Applied Sciences, 2018, Volume 8, pp. 1-16.

17. EN 12350-1. Testing fresh concrete-Part 1: Sampling. European Standard, Brussels: 1999.

18. TS EN 197-1 Cement- Part 1: Compositions and conformity criteria for common cements, Turkish Standards Institute, Ankara, 2002.

19. TS EN 450-1 Used in Fly Ash-Concrete - Part 1: Definitions, characteristics and eligibility criteria, Turkish Standards Institute, Ankara, 2008.

20. Aydos Construction chemicals Chemical analysis report, Aydos Construction Chemicals, 2015.

21. Lund, M.S.M., Hansen, K.K; Hertz, K.D., Experimental investigation of different fill materials in arch bridges with particular focus on Pearl-Chain Bridges, Construction and Building Materials, 2016, Volume (124) pp. 922-936..

22. 12350-6 Testing Fresh concrete, Turkish Standards Institute, Ankara, 2019.

23. 12390-3 Testing Hardened concrete -Part3: Compressive strength of test specimens, Turkish Standards Institute, Ankara, 2010.

24. 12390-6 Testing Hardened concrete -Part6: Tensile splitting strength for test specimens, Turkish Standards Institute, Ankara, 2010.

25. Kuznetsov, E., Pustovgar, A., Ivanova, I., Medvedev, V., Elenova. A., Use of silverbond quartz flour in the design of self-compacting concrete mixtures, 2018, Volume (365) pp. 2-10. 
26. ASTM C666/C666M-15, Standart test method for resistance of concrete to rapid freezing and thawing, 2015.

27. Langaroudi, M.A.M., Mohammadi. Y., Effect of nano-clay on the freeze-thaw resistance of self-compacting concrete containing mineral admixtures, European Journal of Environmental and Civil Engineering, 2019, Volume (2116-7214), pp.1-20.

28. Juradin. S., Vlajic. D., Influence of cement type and mineral additions, silica fume and metakaolin, on the properties of fresh and hardened self-compacting concrete, Mechanical and Materials Engineering of Modern Structure and Component Design,2015, Volume 70, pp. 251-267.

29. Wu. B., Li. Z., Mechanical properties of compound concrete containing demolished concrete lumps after freeze-thaw cycles, Construction and Building Materials, 2017, Volume (155), pp.187-199.

30. Enfedaque, A., Romero. H.L., Galvez. J.C., Fracture energy evolution of two concretes resistant to the action of freeze-thaw cycles, Materials de Construction, 2014, Volume (64), pp.313-321.

31. Wang. Y., Ming. Z., Yu., Z., Hn. S., Ji. W., Durability of reactive powder concrete under chloride salt freeze-thaw cycling, Materials and Structures, 2017, Volume 17, pp.1-18. 